\title{
NANOSTRUCTURED LAYER ENHANCING LIGHT EXTRACTION FROM GAN-BASED SCINTILLATOR USING MOVPE
}

\author{
1,2Tomáš VANĚK*, ${ }^{2}$ Tomáš HUBÁČEK, ${ }^{2}$ František HÁJEK, ${ }^{2}$ Filip DOMINEC, ${ }^{2}$ Jiří PANGRÁC, \\ ${ }^{2}$ Karla KULDOVÁ, ${ }^{2}$ Jiří OSWALD, ${ }^{2}$ Alice HOSPODKOVÁ \\ ${ }^{1}$ Technical University of Liberec, Liberec, Czech Republic, EU, vanekt@fzu.cz \\ ${ }^{2}$ Institute of Physics CAS v.v.i., Prague, Czech Republic, EU
}

https://doi.org/10.37904/nanocon.2020.3698

\begin{abstract}
Light extraction (LE) efficiency of GaN buffer layer was studied by angle-resolved photoluminescence. We measured enhancement of light extraction efficiency (LEE) up to $154 \%$ by introducing the $\mathrm{SiN}_{\mathrm{x}}$ layer atop the GaN buffer and subsequent GaN light extraction layer (LEL) overgrowth. Morphological properties of GaN "islands" forming the LEL, such as size and density, have been tuned by various growth parameters. Subsequently, the influence of different growth parameters, such as coalescence time, time of $\mathrm{SiN}_{\mathrm{x}}$ growth or type of nucleation carrier gas $\left(\mathrm{H}_{2}\right.$ or $\left.\mathrm{N}_{2}\right)$, on LE was discussed. We also experimentally showed that $L E$ of this layer is more efficient for higher extraction angles. Finally, we present the change in the GaN surface morphology by $\mathrm{Si}$ etching in $\mathrm{H}_{2}$ atmosphere during $\mathrm{SiN}_{\mathrm{x}}$ growth (measured by the atomic force microscopy).
\end{abstract}

Keywords: GaN, light extraction, $\mathrm{SiN}_{\mathrm{x}}$, scintillator, MOVPE

\section{INTRODUCTION}

GaN-based heterostructures have been widely studied for more than 30 years since the first blue LEDs were discovered [1]. Nowadays, they are already spread to many LED, LD, and scintillator applications. They are still promising for new applications, thanks to their high luminescence efficiency, high radiation resistance and high exciton binding energy. On the other hand, they have a problem with light extraction due to their high refractive index (approx. 2.38 for green light). A vast scientific effort has been made during the last decade to find the best and commercially reasonable solution. Many different surface treatment techniques like electron beam lithography, laser interface lithography, nanoimprint lithography or anodic aluminum oxide were successfully established [2-9]. Unfortunately, these methods are expensive, time-consuming or unsuitable for large-scale wafer manufacturing and their LEE varies from tens to hundreds of percent, depending on the layer parameters and LEE measuring conditions [10].

The natural light extractors in InGaN/GaN multi-quantum well (MQW) scintillators are V-pits [11]. They form on the top of threading dislocations and their size increases with the thickness of the scintillator active region. In the scintillator case, an enormously thicker active region compared to LEDs is usually necessary due to sufficient radiation stopping power of the scintillator. Consequently, the dimension of $V$-pits in order of hundreds of nanometres is suitable for LE. Furthermore, their surface density is usually around $10^{8} \mathrm{~cm}^{-2}$ for samples grown on the commonly used sapphire substrate. In fact, they cover most of the surface and the light extraction is very efficient. However, threading dislocations are generally a source of nonradiative recombination and the large empty space occupied by V-pits reduces the detection volume of the scintillator. Thus, there is an effort to decrease the number of threading dislocations, which can be realized by using a GaN substrate. The decrease of V-pits surface density about at least two orders of magnitude is achieved, but it causes a substantial reduction in LEE due to the almost flat surface of the scintillator.

In this work, we will show a GaN nanostructured layer grown using a $\mathrm{SiN}_{\mathrm{x}}$ layer on the $\mathrm{GaN}$ buffer layer within a single MOVPE run. The dependency of the surface density of GaN "islands" and their size on the growth 
conditions will be discussed. A significant increase of LEE, thanks to the $\mathrm{GaN}$ overgrowth on the $\mathrm{SiN}_{\mathrm{x}}$ layer and its interesting surface morphology, will be presented as well.

\section{EXPERIMENTAL}

Nine samples of GaN scintillators were prepared by the MOVPE technology in the Aixtron 3x2" CCS MOVPE apparatus equipped with Laytec EpiCurveTT in situ measurement. All samples were grown on the sapphire substrate with the same growth conditions of the first nucleation, coalescence and undoped GaN (uGaN) buffer layer.

The c-oriented sapphire substrate was firstly baked out at $1050^{\circ} \mathrm{C}$ and nitrified by $\mathrm{NH}_{3}$. The $25 \mathrm{~nm}$ thick nucleation layer was grown at $540{ }^{\circ} \mathrm{C}$ and then overgrown by approximately $1.6 \mu \mathrm{m}$ thick undoped GaN layer. Samples A1-A3 were just overgrown by $2.5 \mu \mathrm{m}$ thick $\mathrm{uGaN}$ and $n$-doped $\mathrm{GaN}(\mathrm{nGaN}$ ) layer with temperatures ranging from 1070 to $1080^{\circ} \mathrm{C}$, usually used for subsequent MQW growth, but the influence of these layers on the LE should be negligible in this work. Finally, the $\mathrm{SiN}_{\mathrm{x}}$ layers were grown at $1080{ }^{\circ} \mathrm{C}$ with a growth time ranging from 200 to $400 \mathrm{~s}$. Growth parameters such as nucleation time after SiNx, second coalescence time (CT) and annealing time that have been tuned are listed in Table 1. In situ measurement of reflectance and surface temperature with marked growth steps is shown in Figure 1a.

The scanning electron microscopy (SEM) images were obtained by Philips XL30 ESEM. The atomic force microscope (AFM) Solver P47H-PRO was used for detailed characterization of the surface.

Table 1 List of investigated samples grown with different parameters during and after the $\mathrm{SiN}_{\mathrm{x}}$ layer growth

\begin{tabular}{|c|c|c|c|c|c|c|c|}
\hline Sample & Buffer & $\begin{array}{l}\operatorname{SiN}_{\mathbf{x}} \\
\text { time [s] }\end{array}$ & $\begin{array}{c}\text { Coalescence } \\
\text { time }[\mathbf{s}]\end{array}$ & $\begin{array}{l}\text { Nucleation } \\
\text { carrier gas }\end{array}$ & $\begin{array}{c}\text { Nucleation } \\
\text { time [s] }\end{array}$ & $\begin{array}{c}\text { Annealing } \\
\text { time [s] }\end{array}$ & Comments \\
\hline $\begin{array}{c}\text { DSP } \\
\text { reference } \\
\text { (DR) }\end{array}$ & $\mathrm{uGaN}+\mathrm{nGaN}$ & - & - & - & - & - & $\begin{array}{l}\text { stop growth before } \\
\mathrm{SiN}_{\mathrm{x}} \text { on double-side } \\
\text { polished } \mathrm{Al}_{2} \mathrm{O}_{3}\end{array}$ \\
\hline $\begin{array}{c}\text { SSP } \\
\text { reference } \\
\text { (SR) }\end{array}$ & $\mathrm{uGaN}+\mathrm{nGaN}$ & - & - & - & - & - & $\begin{array}{l}\text { stop growth before } \\
\mathrm{SiN}_{\mathrm{x}} \text { on single-side } \\
\text { polished } \mathrm{Al}_{2} \mathrm{O}_{3}\end{array}$ \\
\hline A1 & $\mathrm{uGaN}+\mathrm{nGaN}$ & 300 & 900 & $\mathrm{H}_{2}$ & 180 & 90 & - \\
\hline A2 & $\mathrm{uGaN}+\mathrm{nGaN}$ & 300 & 200 & $\mathrm{H}_{2}$ & 180 & 90 & - \\
\hline A3 & $\mathrm{uGaN}+\mathrm{nGaN}$ & 300 & 50 & $\mathrm{H}_{2}$ & 180 & 90 & - \\
\hline B1 & uGaN & 200 & 40 & $\mathrm{~N}_{2}$ & 90 & 45 & - \\
\hline B2 & uGaN & 300 & 40 & $\mathrm{~N}_{2}$ & 90 & 45 & - \\
\hline B3 & uGaN & 400 & 40 & $\mathrm{~N}_{2}$ & 90 & 45 & - \\
\hline C & uGaN & 600 & - & - & - & - & $\begin{array}{l}\text { stop growth after } \\
\operatorname{SiN}_{x}\end{array}$ \\
\hline
\end{tabular}
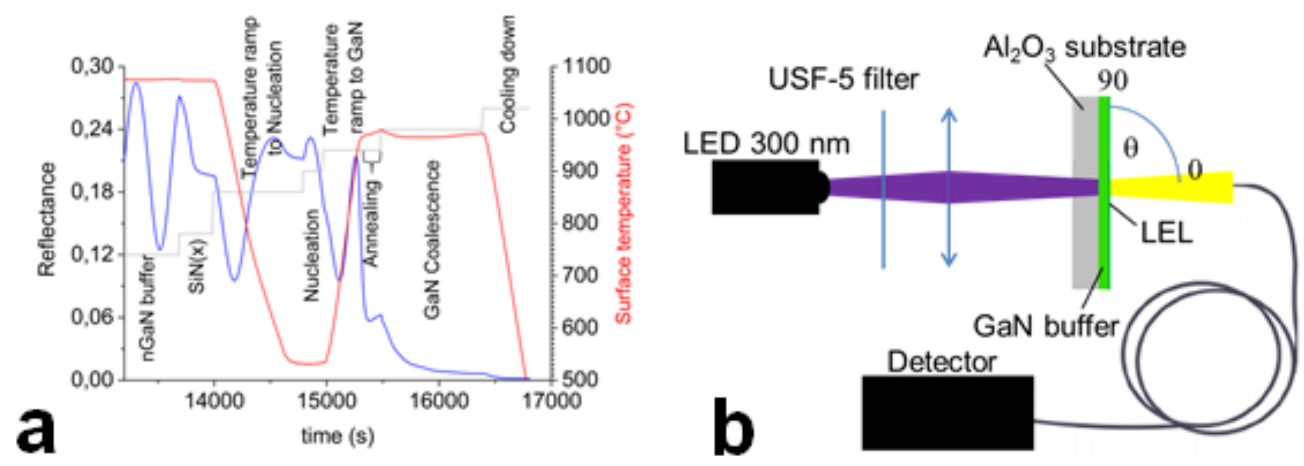

Figure 1 Evolution of reflectance and surface temperature during the growth of $\mathrm{SiN}_{\mathrm{x}}$ and subsequent layers with marked growth steps (a), the scheme of angular dependence PL measurement (b). 
The PL experimental setup is in Figure 1b. Samples were excited through the sapphire substrate with a focused $300 \mathrm{~nm}$ LED filtered by bandpass filter UFS- 5 to suppress parasitic LED luminescence in the visible range. This excitation energy is above the GaN bandgap (3.4 eV 365 nm). Thus, the light is absorbed approximately in the first $150 \mathrm{~nm}$ of the $\mathrm{uGaN}$ buffer. The luminescence light was collected to the optical fiber, which rotated around the sample from 0 to $75^{\circ}$. We didn't measure up to $90^{\circ}$ due to the sample holder suppressing the luminescence from the edge of the scintillators. Light was detected by Thorlabs CCS200 spectrometer with spectral accuracy $<2 \mathrm{~nm}$.

\section{RESULTS AND DISCUSSION}

It has been already published and confirmed by transmission electron microscopy that Ga etches Si from the $\mathrm{SiN}_{\mathrm{x}}$ layer during $\mathrm{GaN}$ overgrowth, which creates a highly Si-doped GaN layer instead of two split layers. Consequently, the highly Si-doped GaN grows in 3D morphology with typical GaN "islands" [12-14]. SEM images in Figures 2a,b show a comparison of sample A1 (with LEL) with the technologically same sample without the LEL (SR). A significant increase of LEE (154\%) was detected by PL measurement, see Figure 2c. Surprisingly, we didn't get the maximum intensity of luminescence in the $0^{\circ}$ for samples with LEL nor SR sample without the LEL, see Figure $\mathbf{2 d}$. We assume it is because of the light scattering on all rough surfaces in the scintillator. In Figure $\mathbf{2} \mathbf{e}$ is shown a comparison of the theoretical transmittance curve, which can be obtained from Snell's law and Fresnel equations, with curves measured by reference samples SR and DR. Equations, used for the calculation, can be written as:

$T=\left[\frac{n_{t} \cos \left(\theta_{t}\right)}{n_{i} \cos \left(\theta_{i}\right)}\right] t^{2} \quad$ where $t^{2}=\frac{\left|E_{0 t}\right|^{2}}{\left|E_{0 i}\right|^{2}}$

where:

$T$ - the transmittance

$n_{t}, n_{i}-$ the refractive indexes of the external and internal medium

$\theta_{t}, \theta_{i}$ - the transmittance and incident angles

$t$ - the ratio between the electrical intensity of transmitted $\mathrm{E}_{0 \mathrm{t}}$ and incidence beam $\mathrm{E}_{0 \mathrm{i}}$
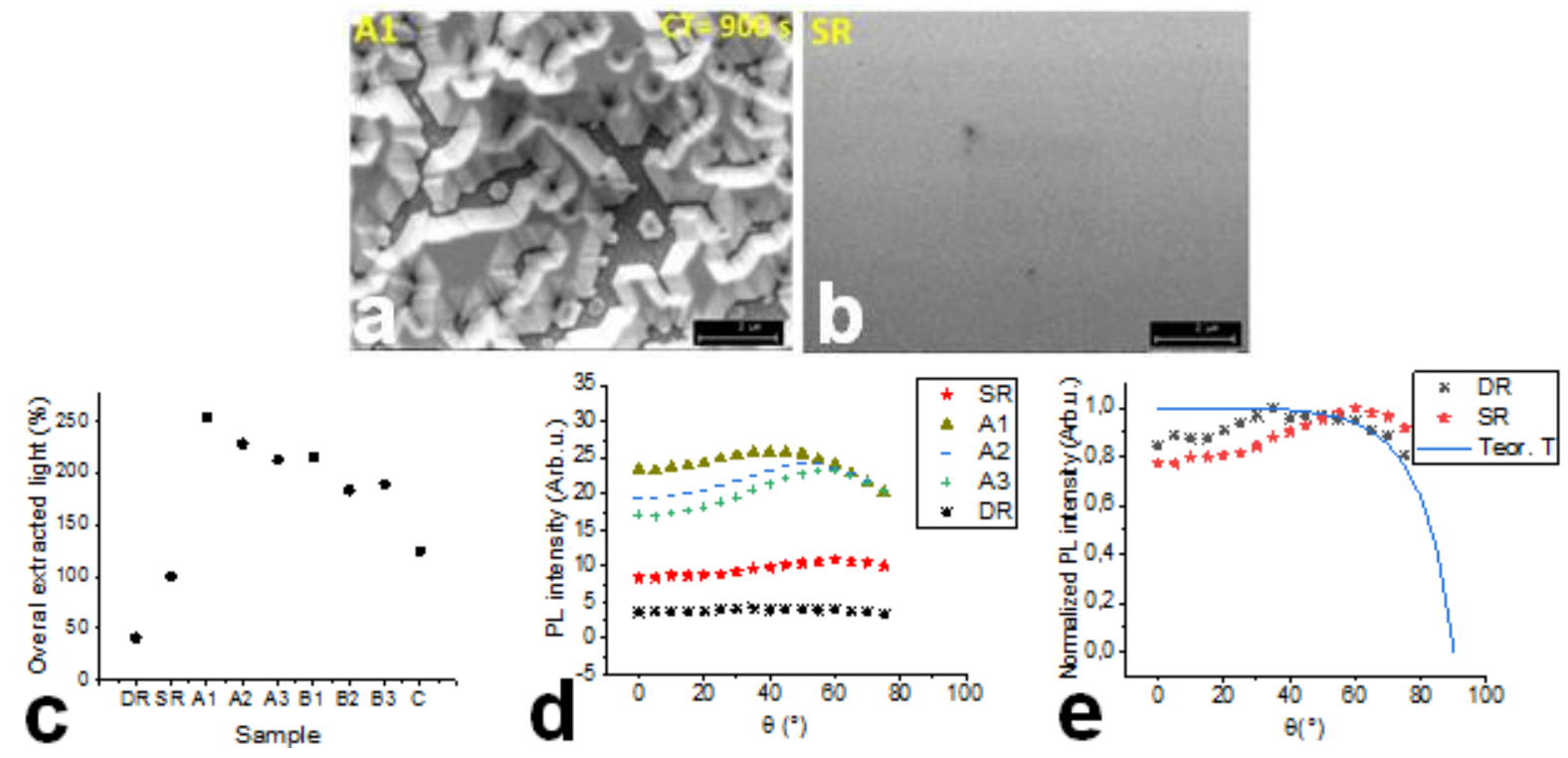

Figure 2 SEM images of sample A1 with the LEL (a) and SR without the LEL (b), a relative comparison of overall light extracted from all angles for all samples (c), angle dependence of PL intensity for individual samples (d), the comparison of the normalized PL intensity of reference samples with theoretical values of transmittance (e). 


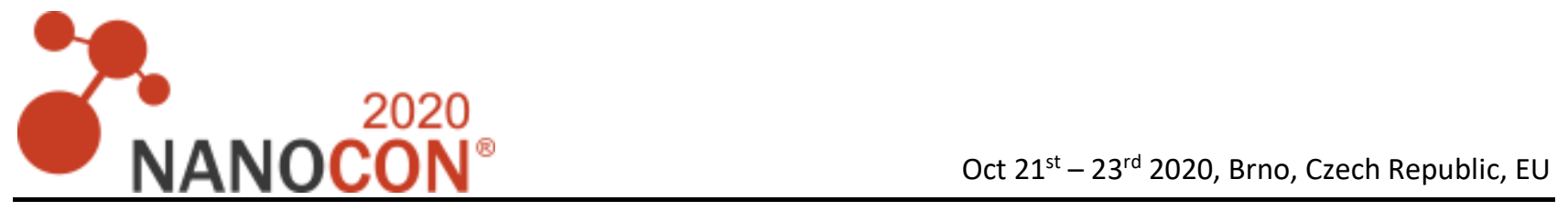

It's clearly seen that the intensity of transmitted light fits very well with theoretical expectations for high extraction angles in the case of the DR sample. The deviation in low angles could be explained by the scattering of light on the interface between the $\mathrm{Al}_{2} \mathrm{O}_{3}$ substrate and $\mathrm{GaN}$, which is a known phenomenon because the crystal quality is very poor there [15].

Generally, it's necessary to approach the dimension of the LEL islands close to luminescence wavelength $\left(\lambda_{\mathrm{em}}\right.$ $=564 \mathrm{~nm}$ ) for the most efficient LE. Furthermore, the luminescence inhomogeneity on this scale produced by the LEL could also be unwanted. Thus, we reduced the coalescence time to create "islands" like the structure shown in Figure 3.
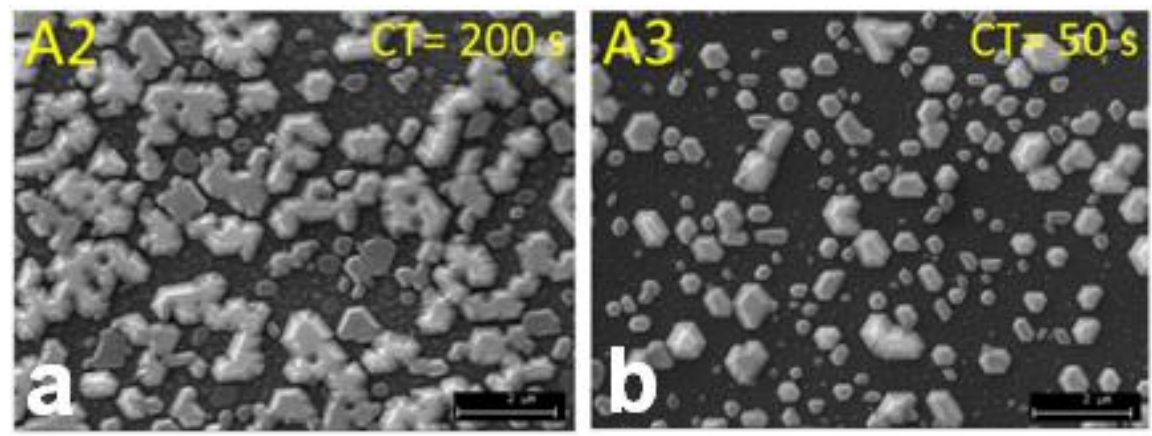

Figure 3 SEM images of samples grown with different coalescence time $200 \mathrm{~s}$ (a), $50 \mathrm{~s}$ (b)

The low density of the GaN islands on the surface causes a decrease in LEE for small angles of extracted light, see Figure 2d for A3. We changed the nucleation carrier gas from $\mathrm{H}_{2}$ to $\mathrm{N}_{2}$ to decrease the surface mobility of atoms and we also dropped nucleation time and annealing time by a factor of two. The result was a slightly higher density of the GaN islands, see sample B2 in Figure 4b. A significant increase in the density occurred with a decreasing time of the $\mathrm{SiN}_{\mathrm{x}}$ layer growth (SiT) to $200 \mathrm{~s}$, Figure $\mathbf{4 a}$. It can be attributed to lower Si doping concentration in the GaN and also a change in surface morphology of the buffer layer, which will be discussed later. An increase of LEE for small extraction angles, due to the higher density of the islands, is clearly observable on the graph in Figure $\mathbf{4 d}$.
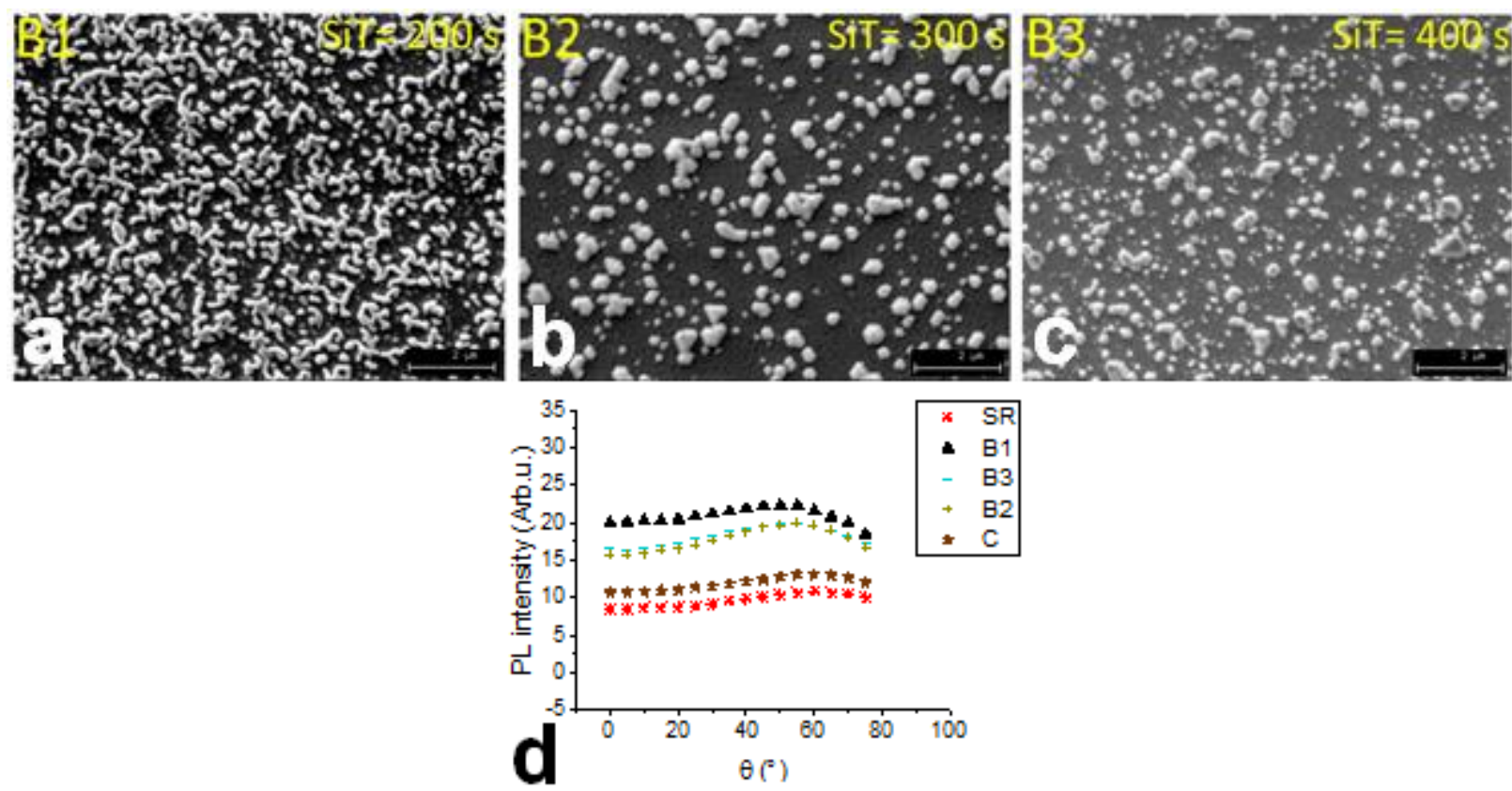

Figure 4 SEM images of samples grown with different times of SiNx growth $200 \mathrm{~s}$ (a), $300 \mathrm{~s}$ (b) and $400 \mathrm{~s}$ (c). Their comparison of PL intensity extracted from individual angles with the SR and C samples (d). 
The ambiguous trend in the decreasing density of the $\mathrm{GaN}$ islands with the increasing growth time of the $\mathrm{SiN}_{\mathrm{x}}$ layer, observable on the sample B3, induces some next mechanism except the higher doping concentration of $\mathrm{Si}$ in GaN. If we zoom in on the surface of the sample B3 (Figure 5a), we can see small black holes indicating a porous morphology of the surface. It is better observable in the AFM image of sample C in Figure $\mathbf{5 b}$ ("stop growth" sample after $600 \mathrm{~s}$ of $\mathrm{SiN}_{\mathrm{x}}$ ). This trenched structure is probably created by the etching of GaN surface by $\mathrm{Si}$ in the $\mathrm{H}_{2}$ atmosphere and its morphology could influence the subsequent GaN growth but this hypothesis needs further investigations. The crater's dimensions are in the order of tens of nanometers in depth and width up to approximately $150 \mathrm{~nm}$ (Figure 5c). These pits, together with trenches, create a partially ordered surface corrugation with a lattice parameter comparable to emission wavelength, similar to photonic structures [10]. We can see, from Figures $\mathbf{4 d}$ and $\mathbf{2 c}$, that enhancement of LEE by this morphology is around $24 \%$ (compare sample $\mathrm{C}$ with $\mathrm{SR}$ ).
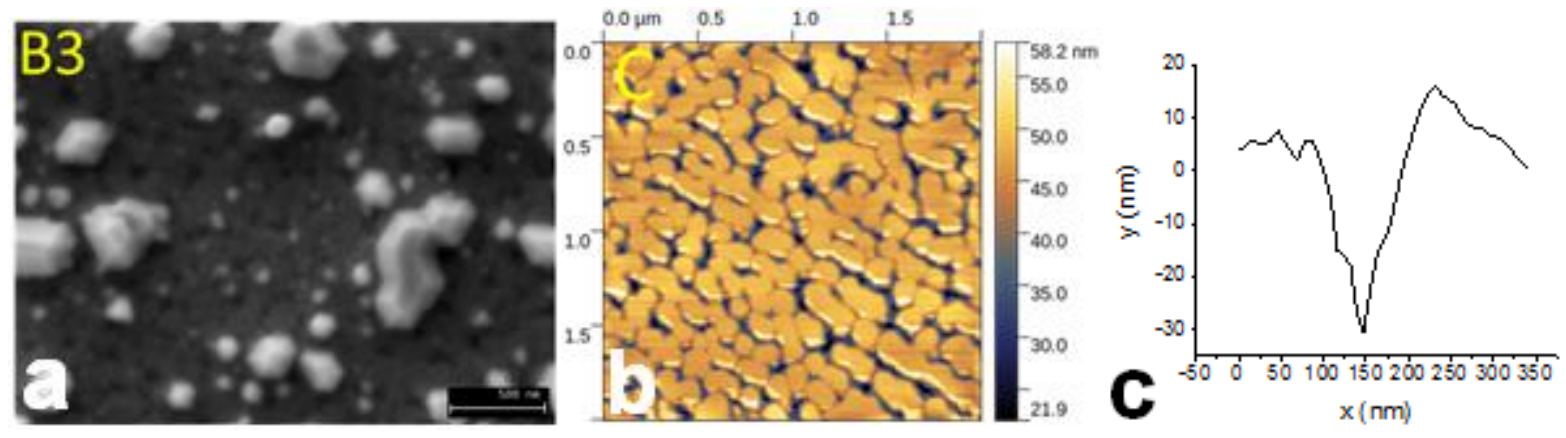

Figure 5 SEM image of the surface of sample B3 (a), AFM image of the $S_{1} N_{x}$ layer morphology (b) and AFM profile of the surface's crater (c).

\section{CONCLUSION}

We have prepared a GaN LEL suitable for LE from GaN-based scintillators. The advantage of this method using the $\mathrm{SiN}_{\mathrm{x}}$ technology is its simplicity and possibility to grow this layer within the single MOVPE run upon the whole two inches wafer surface. Our maximal reached LEE was $154 \%$ for sample A1 compared to the reference sample on a single side polished sapphire substrate, which is comparable with other LEL prepared by different methods. The morphological properties of this layer can be tuned by changing the growth parameters. Concretely, the surface density of the $\mathrm{GaN}$ islands is very sensitive to the growth time of the $\mathrm{SiN}_{\mathrm{x}}$ layer and their size can be easily controlled by coalescence time. At the same time, the results confirm the theory that with increasing concentration of Si doping, GaN tends to 3D growth and creates individual islands. Simultaneously, the $\mathrm{GaN}$ etching by $\mathrm{Si}$ in the $\mathrm{H}_{2}$ atmosphere makes trenches surface morphology, which contributes to LE, too.

\section{ACKNOWLEDGEMENTS}

The authors acknowledge the support of MSMT project no. NPU LO1603 - ASTRANIT.

\section{REFERENCES}

[1] NAKAMURA, S. Growth of $\ln _{x} \mathrm{Ga}_{(1-x)} \mathrm{N}$ compound semiconductors and high-power InGaN/AIGaN double heterostructure violet-light-emitting diodes. Microel. J. 1994, vol. 25, p. 651.

[2] JIN, Y. et al. Enhanced light extraction from a GaN-based green light-emitting diode with hemicylindrical linear grating structure. Opt. Exp. 2012, vol. 20, pp. 15818-15825.

[3] STARK, C. J. M., DETCHPROHM, T. \& WETZEL, C. The Role of Mesa Size in Nano-Structured Green AIGalnN Light-Emitting Diodes. Phys. Stat. Sol. C. 2011, vol. 8, pp. 2311-2314. 
[4] KUO, H. C., YEN, H. H., LEE, C. E. \& CHAO, C. H. Far-field of GaN film-transferred green light-emitting diodes with two-dimensional photonic crystals. Opt. Exp. 2009, vol. 17, pp. 8795-8804.

[5] DONG HYUK, J., HEE KWAN, L. \& JAE SU, Y. Light Output Extraction Enhancement in GaN-Based Green LEDs With Periodic AZO Subwavelength Nanostructure Arrays. Phot. Tech. Lett. IEEE, 2012, vol. 24, pp. 1381-1383.

[6] SANG, H., LEE, K. D., KIM, J. Y., KWON, M. K. \& PARK, S. J. Fabrication of photonic crystal structures on light emitting diodes by nanoimprint lithography. Nanotechnology. 2007, vol. 18, p. 55306.

[7] HUANG, H. W. et al. Enhanced light output from a nitride-based power chip of green light-emitting diodes with nano-rough surface using nanoimprint lithography. Nanotechnology. 2008, vol. 19, p. 185301.

[8] YU, Z. G. et al. Obvious improvement of light extraction obtained by anodic aluminum oxide coverage on GaN surface. App. Phys. A. 2013, vol. 110, pp. 35-39.

[9] YU, Z. G. et al. Optimization of the nanopore depth to improve the electroluminescence for GaN-based nanoporous green LEDs. Mat. Sci. in Sem. Process. 2015, vol. 33, pp. 76-80.

[10] JIANG, S., FENG, Y., CHEN, Z. et al. Study on Light Extraction from GaN-based Green Light-Emitting Diodes Using Anodic Aluminum Oxide Pattern and Nanoimprint Lithography. Scient. Rep. 2016, vol. 6, p. 21573.

[11] HANGLEITERL, A. et al. Suppression of Nonradiative Recombination by V-Shaped Pits in GalnN/GaN Quantum Wells Produces a Large Increase in the Light Emission Efficiency. Phys. Rev. Lett. 2005, vol. 95, p. 127402.

[12] HOSPODKOVA, A. et al. Improvement of GaN Crystalline Quality by SiNx Layer Grown by MOVPE. Lithuanian J. Phys. 2019, vol. 59, no. 4, pp. 185-192.

[13] LAHRECHE, H. et al. Growth of high-quality GaN by low-pressure metal-organic vapor phase epitaxy (LPMOVPE) from 3D islands and lateral overgrowth. J. Cryst. Growth. 1999, vol. 205, no. 3, pp. 245-252.

[14] TANAKA, S. et al. Self-assembling GaN quantum dots on AlxGa1-xN surfaces using a surfactant. Appl. Phys. Lett. 1996, vol. 69, p. 4096.

[15] LIAU, Z. L. et al. Light scattering in high-dislocation-density GaN. Appl. Phys. Lett. 1996, vol. 69, p. 1665. 